\title{
Spontaneous Spinal Epidural Hematoma due to Anticoagulant Therapy: A Case Report and Literature Review
}

\author{
Muhammad-Shukri Muhammad Safian ${ }^{1 \star}$, Rashidah Ismail Ohnmar HTWE ${ }^{2}$, Radhika Sridharan ${ }^{3}$, Ping Hoe $\mathrm{Ngu}^{4^{* \star}}$ \\ AS Naicker ${ }^{5}$
}

${ }^{1}$ Department of Orthopaedics, Hospital Sarikei, Jalan Rentap, 96100 Sarikei, Sarawak, MALAYSIA

${ }^{2}$ Associate Prof / Consultant Rehab Medicine Physician Rehab Medicine Unit, Department of Orthopaedic and Traumatology, Faculty of Medicine, University Kebangsaan, MALAYSIA

${ }^{3}$ Associate Prof Dr / Radiologist Radiology Unit Department of Radiology Faculty of Medicine University Kebangsaan, MALAYSIA

${ }^{4}$ House Officer, Hospital Sungai Buloh, MALAYSIA

${ }^{5}$ Professor / Consultant Rehab Medicine Physician Rehabilitation Unit, Department of Orthopaedic and Traumatology Faculty of Medicine Universiti Kebangsaan MALAYSIA

*Corresponding Author: shukrisafian.ortho@gmail.com

${ }^{\star \star}$ Corresponding Author: ric.phngu@gmail.com

Citation: Muhammad-Shukri MS, Rashidah Ismail Ohnmar HTWE, Sridharan R, Ngu PH, A S Naicker. Spontaneous Spinal Epidural Hematoma due to Anticoagulant Therapy: A Case Report and Literature Review. Electron J Gen Med. 2020;17(3):em197. https://doi.org/10.29333/ejgm/7820

\section{ARTICLE INFO ABSTRACT}

Received: 30 Jan. 2020

Aims: We report a case of spontaneous spinal epidural hematoma (SSEH) that occurred in a patient on life-long Accepted: 04 Sep. 2020 warfarin following liver transplant due to decompensated liver failure secondary to primary Budd-Chiari syndrome.

Patients and Methods: Our patient presented with acute central back pain with bilateral lower limb paralysis and incontinence with neurological level of T8 American Spinal Injury Association Impairment Scale (AIS) A. There were no history of fever, trauma or straining. MRI revealed a hyper-intense lesion at level of T8 till T10 and patient underwent an urgent laminectomy which revealed an epidural hematoma at that level.

Result: Post-operatively, patient gradually improved with final neurology level at level of T9 AIS D prior to discharge.

Conclusion: A prompt diagnosis and intervention are needed in cases of SSEH to achieve a favourable outcome.

Keywords: Spinal epidural hematoma, anticoagulation, warfarin

\section{INTRODUCTION}

Spontaneous spinal epidural hematoma (SSEH) is a rare disease with an estimated incidence of 0.1 in 100000 per year (1). It is associated with acute neurological deficit that warrants an urgent detection and treatment to achieve the best possible outcome $(1,2)$. Majority of patient will present with an acute back pain with neurological deficit that will usually correspond with the level of compression by the hematoma (2-4). A multifactorial aetiology is suggested and the usage of anticoagulant has been implicated as a possible cause and associated with a poor outcome $(1,2,5,6)$. We would like to report on a case of SSEH occurring in a patient on life-long warfarin treatment that have a favourable outcome following surgical treatment and supervised rehabilitation.

\section{CASE SUMMARY}

A 34 years old middle east gentleman presented to our centre with the complaint of acute central backpain with progressive lower limb weakness that progresses to a total lower limb paralysis and incontinence roughly 12 hours after the onset of pain. On further history, he was on life-long warfarin following a liver transplant in March 2016 due to decompensated liver failure secondary to primary Budd-Chiari syndrome. Otherwise, there were no history of fever, trauma or significant straining. Examination revealed neurology grade of American Spinal Injury Association Impairment Scale (AIS) A at level of T9 with absent sacral functions. Laboratory investigations revealed coagulopathy with elevated prothrombin time (PT) of 54.9 seconds (control, 11.6 - 14.1 seconds), activated partial thromboplastin time (aPTT) of 68.6 seconds (control, 30.1 - 44.3 seconds) and international normalized ratio (INR) of 6.17 (therapeutic range $2.5-4.0$ ). MRI revealed an intra-spinal extra-dural lesion at level of T8 - T10 that was suggestive of an epidural hematoma (Figure 1 and 2). Warfarin was withheld and patient was given 4 units of fresh frozen plasma (FFP). The coagulopathy was managed to be controlled on day 2 of admission and patient then underwent an urgent decompression (laminectomy) at T9 level.

Post-operatively, patient was started on a supervised rehabilitation with our physiotherapist and the brother was included and trained as a care-giver. Patient then improved gradually in terms of bed mobility and managed to transfer 


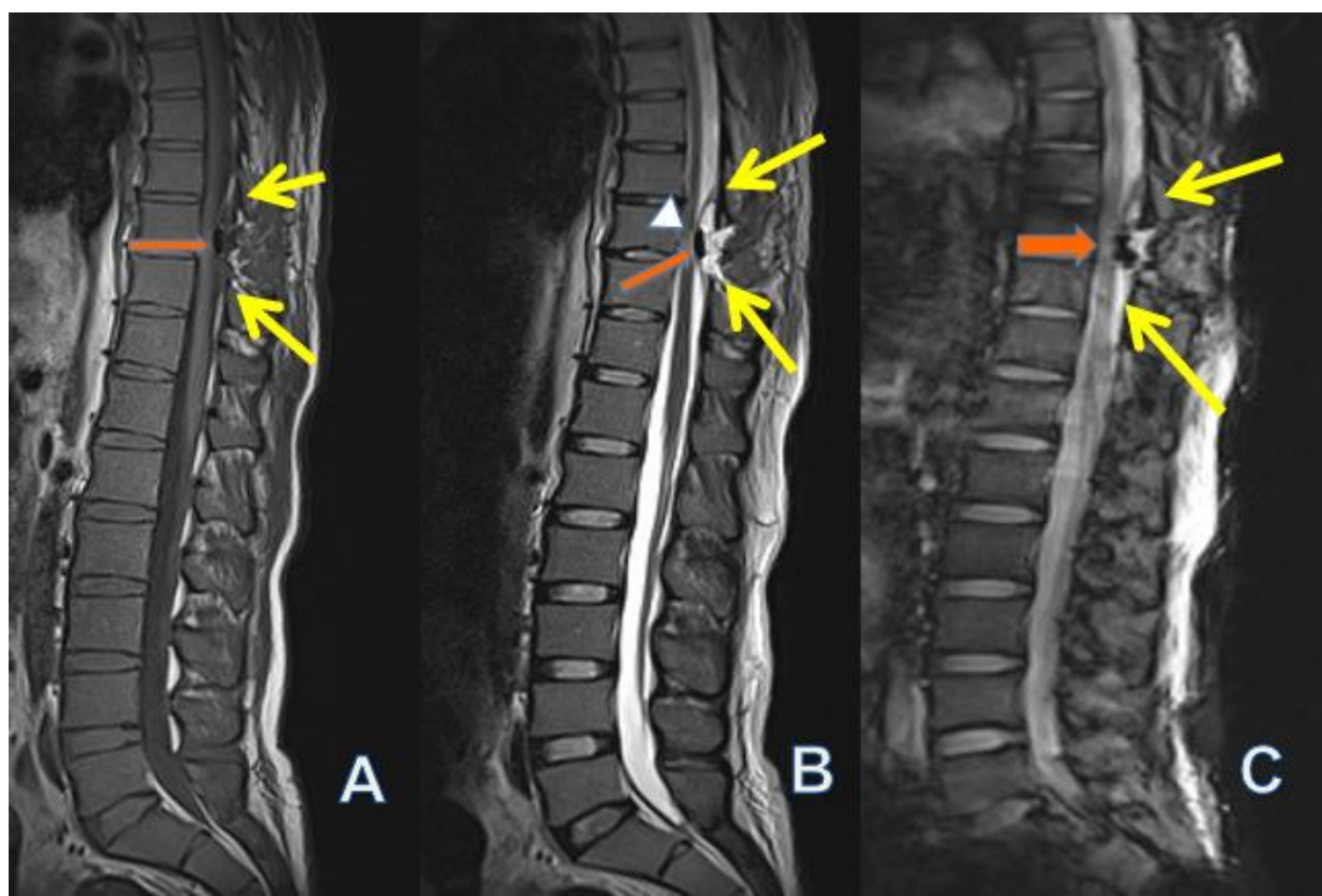

Figure 1. Sagittal magnetic resonance imaging of the patient; T1WI (A), Sagittal T2WI (B) and Sagittal Gradient Echo Images (C). Well defined broad based posterior intraspinal, extradural mass seen from T8 till T10 vertebral levels (yellow arrows). The lesion is predominantly iso to hypointense on T1WI (A) and hyperintense on T2WI (B). There is hemosiderin (chronic blood products) evident at the anterior aspect of the lesion which demonstrates blooming artifact in the gradient echo sequence (C) (red arrows). The lesion is compressing onto the cord anteriorly with evidence of cord oedema (B) (white arrowhead)

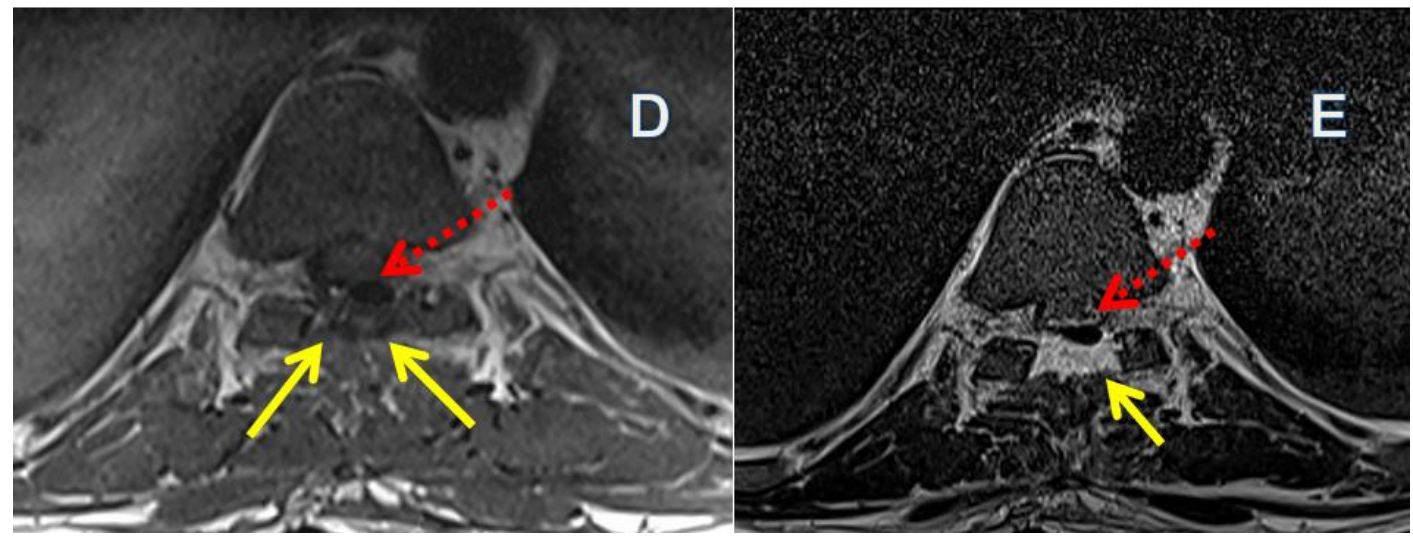

Figure 2. Axial magnetic resonance imaging of the patient; T1WI (D) and axial T2WI (E) shows the intraspinal extradural lesion which is predominantly iso to hypointense on T1WI and hyperintense on T2WI (yellow arrows). The dark focus seen at the anterior aspect of the lesion represents hemosiderin (dotted red arrow)

with minimal carer assistance. Patient was also able to mobilize with a wheelchair. His neurology level improved up to AIS D with best level at T9 however, he still has bladder and bowel dysfunction and required an in-dwelling urinary catheter. Patient was otherwise discharged with wheelchair ambulation. During his last clinic review at two months, he was already able to walk short distance approximately 50 metres with the aid of a walking stick and had already regained his bladder and bowel control.

\section{DISCUSSION}

Anti-coagulant usage has been implicated as one of the risk factor that predisposed a patient to develop SSEH; several case reports and meta-analysis reported on this finding and the rate was reported to be in between $16-30 \%(1-3,7-9)$. In the most recent article by Raasck et al, 4 out of their 6 patients were on anti-coagulant; 2 were on warfarin and 2 were on daily aspirin (2). Earlier, Tawk et al reported of 3 cases that developed SSEH while on anti-coagulant therapy with no apparent precipitating event (8). Thus, in patients on anti-coagulant therapy, the diagnosis of SSEH should be one of the main differentials if they present with an acute spinal cord compression.

To aid clinicians in the diagnosis, magnetic resonance imaging (MRI) is the imaging of choice $(7,10)$. Not only can it help in confirming the diagnosis, it can also exclude other possible lesions such as acute prolapsed disc, spinal tumours or infection $(5,10)$. Features that points toward a hematoma include a lesion which is isointense to the cord on T1 weighted image while being hyperintense on $\mathrm{T} 2$ weighted image and might show peripheral enhancement on contrasted image 
$(7,10)$. In our case, MRI was invaluable as the initial differentials on patient presentation was actually transverse myelitis and spinal abscess rather than epidural hematoma. It helped us in arriving to the diagnosis and initiating an appropriate treatment for the patient.

Spinal epidural hematoma may happen from the upper cervical level up to the lumbar level with junctional area at the cervico-thoracic and thoraco-lumbar junction being the most common area (1-3). Other than that, it is commonly present at multiple levels commonly affecting $2-5$ levels and located mainly at the dorsal or dorso-lateral side (3). Why does this anatomic localization more common? Some authors attribute the bleed to the venous epidural plexus that is located mainly at the dorsal aspect (3). This plexus is prone to the undulating thoracic and abdominal pressure thus any sudden increase may cause rupture (9). Other than that, the dorsal epidural space is filled with fatty tissue and is more readily displace compared to the anterior epidural space making it easier to spread to multiple levels (3).

However, Raasck et al do not believe that the origin is clinically important and is more of an academic interest as the most important prognostic factor is the time between onset to detection and intervention (2). This time factor is also supported by other reports (4). Patient tend to do better if surgical intervention is done within $12-24$ hours of symptoms onset (2). In our case, it was delayed as we need to take the coagulopathy into account as we felt it would be risky to do surgery in the setting of poor coagulation.

Other factors that may affect outcome includes initial neurologic status and extent of the hematoma $(1,2,11)$. Good outcome as defined by Bakker et al. is recovery of initial neurological deficit of Frankel A or B to at least Frankel C on last follow up or if initial presentation was Frankel $C$ or $D$, improvement of at least one class is needed; A poor outcome is seen mainly in patients with initial complete neurological deficit (Frankel A), delayed surgical decompression of more than 24 hours and hematoma at junctional vertebrae level (1). Prior to discharge, our patient still has neurological deficit of AIS C with bladder and bowel dysfunction however, at 2 months he was already ambulating with a walking stick and regained his bladder function (AIS B) thus outcome in our patient is considered as favourable.

\section{CONCLUSION}

A diagnosis of SSEH should always be considered in patient that present with backpain with associated neurological deficit especially if the patient is on anti-coagulants or in coagulopathy. A prompt diagnosis and intervention are needed to achieve a favourable outcome.

\section{Conflict of Interest}

The authors declare they have no conflict of interest that are directly or indirectly related to the report.

\section{Ethical Statement}

Informed consent has been obtained from the patient prior to the writing of this report for publication purposes.

\section{Funding Sources}

No funding was received for this report.

\section{REFERENCES}

1. Bakker NA, Veeger NJGM, Vergeer RA, Groen RJM. Prognosis after Spinal Cord and Cauda Compression in Spontaneous Spinal Epidural Hematomas. Neurology 2015;84:1894-903. https://doi.org/10.1212/WNL.0000000000001545 PMid:25862799

2. Raasck K, Habis AA, Aoude A, Simões L, Barros F, Reindl R, Jarzem P. Spontaneous Spinal Epidural Hematoma Management: A Case Series and Literature Review. Spinal Cord Ser Cases 2017;16043. https://doi.org/10.1038/ scsandc.2016.43 PMid:28382214 PMCid:PMC5289268

3. Kreppel D, Antoniadis G. Seeling W. Spinal Hematoma: A Literature Survey with Meta-analysis of 613 Patients. Neurosurg Rev 2003;26(1):1-49. https://doi.org/10.1007/ s10143-002-0224-y PMid:12520314

4. Groen RJM. Non-operative Treatment of Spontaneous Spinal Epidural Hematomas: A Review of the Literature and a Comparison with Operative Cases. Acta Neurochir (Wien) 2004;146:103-10. https://doi.org/10.1007/s00701-0030160-9 PMid:14963742

5. Baek BS, Hur JW, Kwon KY, Lee HK. Spontaneous Spinal Epidural Hematoma. J Korean Neurosurg Soc 2008;44:40-2. https://doi.org/10.3340/jkns.2008.44.1.40 PMid:19096655 PMCid:PMC2588288

6. Henderson RD, Pittock SJ, Piepgras DG, Wijdicks EFM. Acute Spontaneous Spinal Epidural Hematoma. Arch Neurol 2001;58:1145-6. https://doi.org/10.1001/archneur. 58.7.1145 PMid:11448306

7. Fukui MB, Swarnkar AS, William RL. Acute Spontaneous Spinal Epidural Hematomas. AJNR Am J Neuroradiol 1999;20:1365-72.

8. Tawk C, Moussa MEH, Zgheib R, Nohra G. Spontaneous Epidural Hematoma of the Spine Associated with Oral Anticoagulants: 3 Case Studies. Int J Surg Case Rep 2015;13:8-11. https://doi.org/10.1016/j.ijscr.2015.05.022 PMid:26074484 PMCid:PMC4529632

9. Htwe O, Naicker AS, Pei TS. Spinal epidural hematoma due to anticoagulant therapy: A case report and literature review. Eur J Gen Med 2016;13(3):61-2. https://doi.org/10.29333/ejgm/81908

10. Matsumura A, Namikawa T, Hashimoto R, Okamoto T, Yanagida I, Hoshi M, Noguchi K, Takami M. Clinical Management for Spontaneous Spinal Epidural Hematoma: Diagnosis and Treatment. Spine J 2008;8:534-7. https://doi.org/10.1016/j.spinee.2007.01.009 PMid:17434807

11. Falavigna A, Righesso O, Teles AR, Hoesker T. Spontaneous Idiopathic Spinal Epidural Hematoma: Two Different Presentations of the Same Disease. Coluna/Columna 2010;9(3):338-42. https://doi.org/10.1590/S1808-18512010 000300016 